\title{
Effects of pyriproxyfen exposure on damage to midgut and related gene expressions in the Bombyx mori silkworm
}

\author{
Huimin Guo ${ }^{\mathrm{a}, \uparrow}$, Xiao Zhang ${ }^{\mathrm{a}, \uparrow}$, Juan Sun ${ }^{\mathrm{a}}$, Xin Zheng ${ }^{\mathrm{a}}$, Guodong Zhao ${ }^{\mathrm{a}, \mathrm{b}}$, Gang Li ${ }^{\mathrm{a}, \mathrm{b}}$, Heying Qian ${ }^{\mathrm{a}, \mathrm{b}, *}$ \\ a School of Biotechnology, Jiangsu University of Science and Technology, Jiangsu 212018 China \\ b Sericultural Research Institute, Chinese Academy of Agricultural Sciences, Jiangsu 212018 China \\ *Corresponding author, e-mail: qhysri@just.edu.cn \\ $\dagger$ These authors contributed equally to this work.
}

Received 5 Jul 2021

Accepted 8 Oct 2021

\begin{abstract}
Silkworm is an important economic insect and very sensitive to pesticides. The pollution of pyriproxyfen leads to the detriment of the growth and cocooning of the silkworm, which seriously affects the development of sericulture. Results showed that at $24 \mathrm{~h}$ and $48 \mathrm{~h}$ after pyriproxyfen exposure, the relative expressions of digestive enzyme genes, oxidative phosphorylation genes, and antioxidant enzyme genes were reduced, suggesting the inhibition of pyriproxyfen on digestion and absorption, energy metabolism, and antioxidation in the midgut of a silkworm. However, the activities of detoxification enzymes and the expressions of detoxification-related genes were elevated in the midgut of silkworm after $24 \mathrm{~h}$ and $48 \mathrm{~h}$ of pyriproxyfen exposure, indicating the enhanced resistance of silkworm to pyriproxyfen. In general, this study revealed the silkworm's midgut response to pyriproxyfen and provided an important reference to understand the metabolic mechanism of pyriproxyfen in this insect.
\end{abstract}

KEYWORDS: pyriproxyfen, digestion and absorption, antioxidation, detoxification, silkworm

\section{INTRODUCTION}

Bombyx mori, or silkworm is an important economic insect and vulnerable to adverse environmental effects, including virus infection and pesticide poisoning, due to its long-term indoor isolation and poor stress resistance $[1,2]$. As a chitin synthesis inhibitor of alkoxypyridine juvenile hormone [3], pyriproxyfen can prevent insects from forming new epidermis when molting, thus hindering metamorphosis or even causing deforming and death of the insects $[4,5]$. Pyriproxyfen is one of the most widely used insecticides at present because of its low toxicity and high efficiency. However, the phenomenon of non-cocooning of Bombyx mori in major silkworm areas in China appeared in recent years, which was attributed to the intake of mulberry leaves polluted by pyriproxyfen pesticides, suggesting the sensitivity of Bombyx mori to pyriproxyfen.

The midgut is the digestive organ of silkworms, and it is mainly responsible for the digestion and absorption of nutrients. Meanwhile, the midgut is the first barrier against foreign substances, such as pathogens or pesticides, that pass through the midgut before entering other tissues and organs.
Previous studies have shown that trace amounts of pesticides can cause damages to the midgut of silkworm and affect its digestion and absorption functions, as well as the physiological and biochemical indexes of the body [6]. For instance, low-dose pesticides cause the accumulation of reactive oxygen species (ROS) and the decrease in antioxidant enzyme activity of silkworms [7]. The increased activity of detoxification enzymes of silkworm indicated its stress response to external adverse factors and its improvement of environmental adaptability $[6,8,9]$.

In the present study, we aimed to investigate the damages of pyriproxyfen exposure on the midgut and to evaluate the relative expression levels of genes associated with various signaling pathways and the detoxification process. The elucidation of the responses of silkworms to pyriproxyfen will provide a conclusive value to prevent pesticide pollution in silkworms.

\section{MATERIALS AND METHODS \\ Insect strains and chemicals}

The silkworm strain Jingsong was preserved in Sericultural Research Institute, Chinese Academy 
of Agricultural Sciences. The larvae were reared with mulberry leaves at $28 \pm 1{ }^{\circ} \mathrm{C}$ with $85 \%$ relative humidity at the age from the 1st instar to the 3rd instar, and at $25 \pm 1{ }^{\circ} \mathrm{C}$ with $70 \%$ relative humidity at the age from the 4th instar to the 5th instar [10].

Pyriproxyfen (analytical grade) was purchased from Sigma-Aldrich Company (Shanghai, China): IUPAC chemical name: 4-phenoxyphenyl (RS)-2-(2pyridyloxy) propyl ether, 95\% purity. All the other general chemical reagents were purchased from Sangon Biotech (Shanghai) Co., Ltd.

\section{Sample preparation}

Pyriproxyfen was dissolved in acetone. To ensure the survival rate of the silkworm, the dose of pyriproxyfen was far lower than the recommended concentration in the field [11]. The stock solution was diluted with $\mathrm{ddH}_{2} \mathrm{O}$ to a final concentration of $0.001 \mathrm{mg} / \mathrm{l}$ as a working solution [12]. Mulberry leaves were treated by an immersion method. Briefly, mulberry leaves were soaked in the working solution for $1 \mathrm{~min}$ and then dried naturally.

The silkworm larvae were fed normally with fresh mulberry leaves from the 1st instar to the 3rd day of the 5th instar. On the 4th day of the 5th instar, the larvae were divided into two groups: a control group and a treatment group. Each group consisted of three individual replicates of 40 larvae with a total of 120 larvae; and among them, two sub-groups of 60 larvae were used for statistical analysis and anatomical materials, respectively. In the control group, the larvae were fed with mulberry leaves treated with $\mathrm{ddH}_{2} \mathrm{O}$ from the 4th day until mounting. In the treatment group, the larvae were fed with mulberry leaves treated with $0.001 \mathrm{mg} / \mathrm{l}$ pyriproxyfen until molting. After treatments, silkworms from both groups were dissected at $24 \mathrm{~h}$ intervals and the midgut tissues were collected.

\section{Histopathological evaluation of midgut}

Three midguts were randomly selected from each group and fixed in $4 \%$ formalin, and then embedded in paraffin. Sections $(5 \mu \mathrm{m})$ were sliced from the paraffin blocks, fixed on the flakes, stained with hematoxylin-eosin, and then observed under optical microscopy (Nikon U-III Multipoint Sensor System, USA).

\section{Measurement of detoxification enzyme activities}

At $24 \mathrm{~h}$ and $48 \mathrm{~h}$ after pyriproxyfen exposure, $100 \mathrm{mg}$ of midguts from the control and the treatment groups were isolated and separately placed in the grinding tubes. Subsequently, $1 \mathrm{ml}$ of cell lysis buffer and $10 \mu \mathrm{l}$ of PMSF were added into each tube. When the tissues were fully ground and lysed, the samples were centrifuged, and the supernatants containing proteins were saved and stored at $-80^{\circ} \mathrm{C}$ until further processing. P450, GST, and CarE enzyme assay kits were purchased from Jiancheng Bioengineering Institute (Nanjing, China). The detoxification enzyme activity was measured following the manufacturer's instructions, and the total protein levels were determined by the Bradford method.

\section{Isolation of total RNA and RT-PCR}

At $0,24,48,72$, and $96 \mathrm{~h}$ after pyriproxyfen exposure, the midguts of larvae were quickly dissected and collected. TRIzol reagent was used to extract total RNA from the midguts, followed by the DNase treatment to remove potential genomic DNA contamination. First-strand cDNA was synthesized with M-MLV Reverse Transcriptase and oligo (dT) primer following the manufacturer's instructions. All reagents were from Takara, Dalian, China except the primer was from Sangon, Shanghai, China. The quality of RNA was assessed by formaldehyde agarose gel electrophoresis, followed by spectrophotometric quantification.

\section{Quantitative real-time PCR (qRT-PCR) analysis}

The primers used for qRT-PCR (Table S1) were designed using primer (6.0) software and synthesized by Shanghai Biotechnology Co., Ltd. SYBR Prime Script $^{\mathrm{TM}}$ RT-PCR kit was used for the determination on ABI Prism 7300 Fluorescence Quantitative PCR Instrument (Applied Biosystems, USA). The specific experimental steps were in accordance with the instructions, and the reaction system was $20 \mu 1$. The reaction procedure was: denaturation at $95^{\circ} \mathrm{C}$ for $1 \mathrm{~min}$; followed by 40 cycles of: $15 \mathrm{~s}$ at $95^{\circ} \mathrm{C}$ and $31 \mathrm{~s}$ at $60^{\circ} \mathrm{C}$. All the control and treatment samples were measured, and the data were expressed by the mean \pm standard error of three independent experiments.

\section{RESULTS}

\section{The pathological evaluation of midgut}

Via microscopic observation of tissue sections, the pathological changes of the silkworm midgut at the 4th day of the 5th instar were further examined after being poisoned with $0.001 \mathrm{~g} / 1$ pyriproxyfen. As shown in Fig. 1, in the control group, the midgut structure of the larvae was intact, indicating the good condition for cell growth. Compared with the 


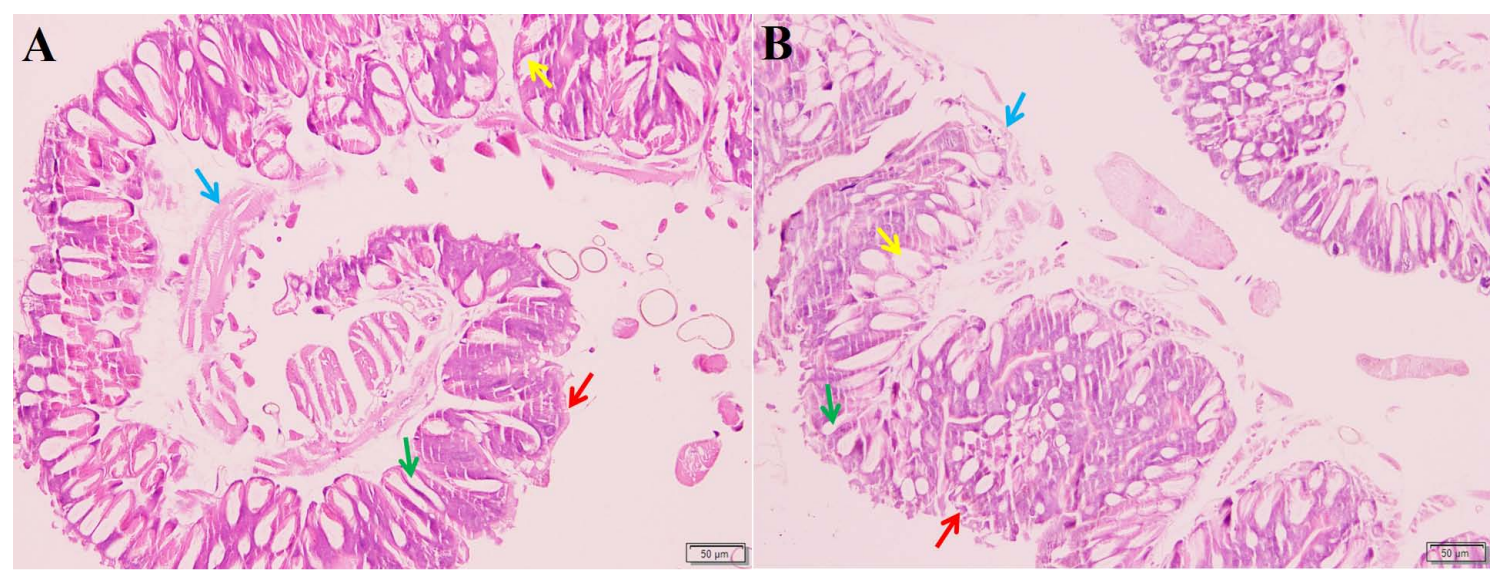

Fig. 1 Histopathology of the midgut in the 5th instar larvae of silkworm: (A) midgut from the control group; (B) midgut from the treatment group. The different arrow colours indicate: red, muscle layer; yellow, cylindrical cells; green, goblet cells; and blue, peritrophic matrix.

midgut wrapped by the outer muscle layer of the control group (Fig. 1A), the midgut muscle layer of the pyriproxyfen-fed larvae almost disappeared and shattered (Fig. 1B). In addition, the cylindrical cells and the goblet cells in the control group were intact (Fig. 1A), but the cells in the treatment group were severely damaged with blurred structure (Fig. 1B), which may be caused by the rupture of the cell membrane and the outflow of cell contents.

Owing to the protection of the peritrophic matrix of the midgut on the intestinal wall, serious lesions could be caused when the peritrophic matrix is attacked by foreign substances. Similarly, our study showed that the peritrophic matrix of the control group was relatively intact (Fig. 1A), while the peritrophic matrix of the treatment group was basically destroyed (Fig. 1B).

\section{Changes in the expression of genes related to digestion after pyriproxyfen exposure}

With various types of secreted enzymes, the midgut of the silkworm serves as the main organ of food digestion and nutrition absorption. As shown in Fig. 2, the overall expression level of genes related to digestion and absorption in the treatment group was lower than that in the control group. Specifically, the expression levels of $\alpha$-amylase, Trypsinlike protease, and Lipase 1 in the treatment group were significantly decreased at $24 \mathrm{~h}(0.27,0.32$, and 0.94 fold, respectively) compared with the control group. At $48 \mathrm{~h}$, the levels of $\alpha$-amylase, Trypsinlike protease, and Lipase 1 in the treatment group were $0.98,0.07$, and 0.84 fold as much as that in the control group.

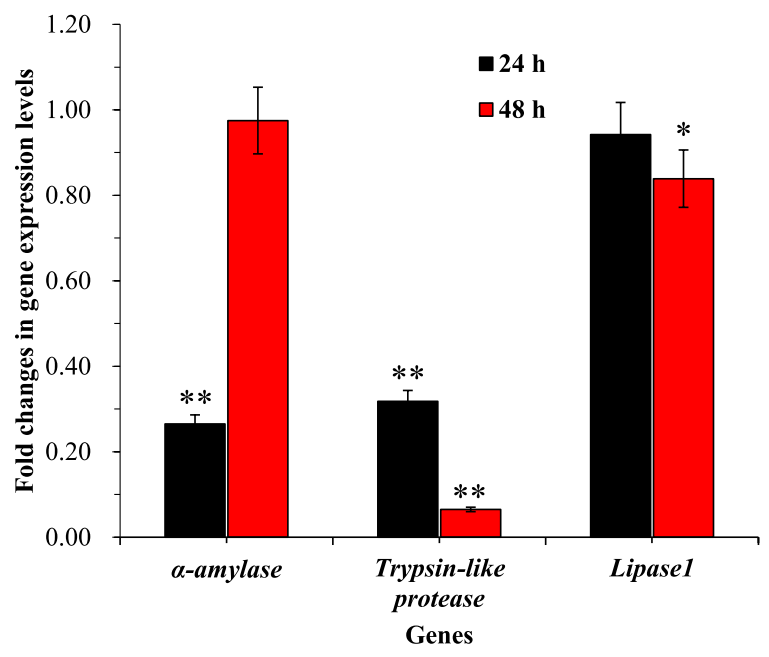

Fig. 2 Effects of pyriproxyfen exposure at $24 \mathrm{~h}$ and $48 \mathrm{~h}$ on expression levels of genes related to digestion and absorption in the midgut. Abscissa represents different genes, and ordinate represents fold changes in gene expression levels. The results are shown as the mean \pm S.E. Asterisks denote significant differences between the treatment and the control groups, as indicated by * $p \leqslant 0.05$, and $* * p \leqslant 0.01$.

\section{Changes in the expression of genes related to oxidative phosphorylation after pyriproxyfen exposure}

Oxidative phosphorylation is a process in which energy released by organic matter is used to produce ATP during oxidative degradation in the body. The expression levels of genes related to oxidative phosphorylation were all decreased after pyriproxyfen 


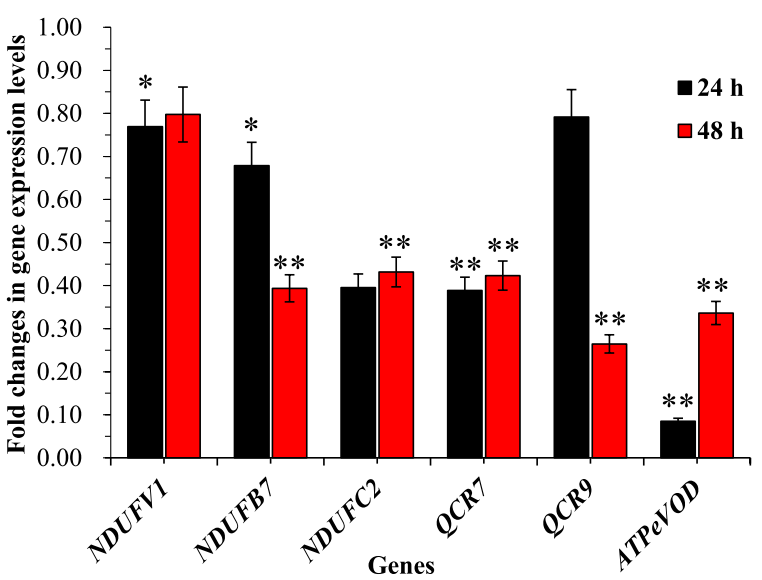

Fig. 3 Effects of pyriproxyfen exposure at $24 \mathrm{~h}$ and $48 \mathrm{~h}$ on expression levels of genes related to oxidative phosphorylation in the midgut. Abscissa represents different genes, and ordinate represents fold changes in gene expression levels. The results are shown as the mean \pm S.E. Asterisks denote significant differences between the treatment and the control groups, as indicated by * $p \leqslant 0.05$, and $* * p \leqslant 0.01$.

exposure. As shown in Fig. 3, the expression levels of NDUFV 1, NDUFB 7, NDUFC 2, QCR 7, QCR 9, and $A T P e V O D$ in the treatment group were $0.77,0.68$, $0.40,0.39,0.79$, and 0.09 times of those in the control group at $24 \mathrm{~h}$ after treatment, respectively; and the levels were $0.80,0.39,0.43,0.42,0.27$, and 0.34 times at $48 \mathrm{~h}$, respectively.

Changes in the expression of genes related to antioxidation after pyriproxyfen exposure

SOD, GST, GPX, and CAT are antioxidant-related genes in the midgut of silkworm. The expression levels of these genes were detected after pyriproxyfen exposure. As seen in Fig. 4, at $24 \mathrm{~h}$ after pyriproxyfen exposure, the expression levels of $S O D$, GST, GPX, and CAT genes in the treatment group were $0.92,0.97,0.99$, and 0.31 times of those in the control group, respectively; and the level at $48 \mathrm{~h}$ after the exposure were $0.89,0.61,0.69$, and 0.30 times of those in the control group, respectively. Hence, pyriproxyfen exposure decreased the expression levels of SOD, GST, GPX, and CAT with significant alteration at $48 \mathrm{~h}$.

\section{The effects of pyriproxyfen exposure on the expression of detoxification-related genes}

The detoxification ability of detoxifying enzymes in silkworm reflects its resistance to the pesticide to some extent. In this study, qRT-PCR was

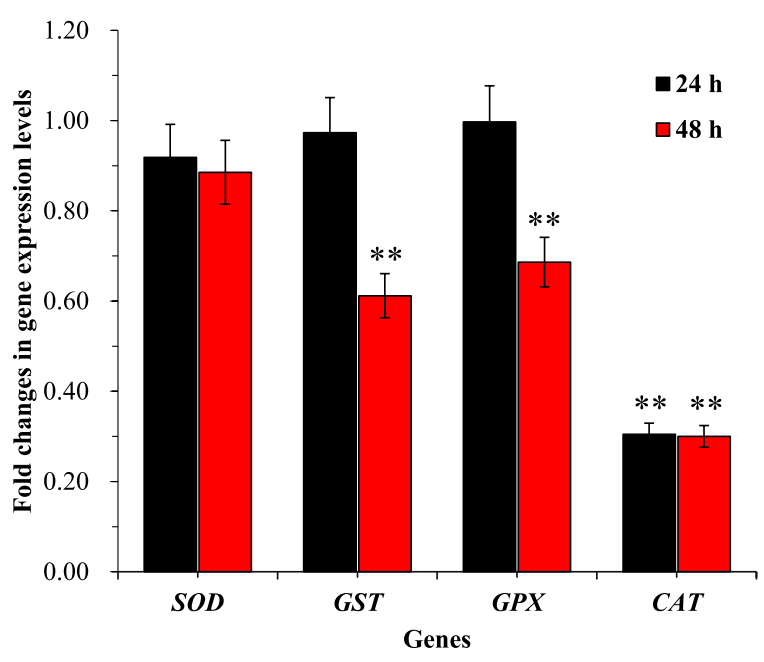

Fig. 4 Effects of pyriproxyfen exposure at $24 \mathrm{~h}$ and $48 \mathrm{~h}$ on expression levels of genes related to antioxidation in the midgut. Abscissa represents different genes, and ordinate represents fold changes in gene expression levels. The results are shown as the mean \pm S.E. Asterisks denote significant differences between the treatment and the control groups, as indicated by * $p \leqslant 0.05$, and ** $p \leqslant 0.01$.

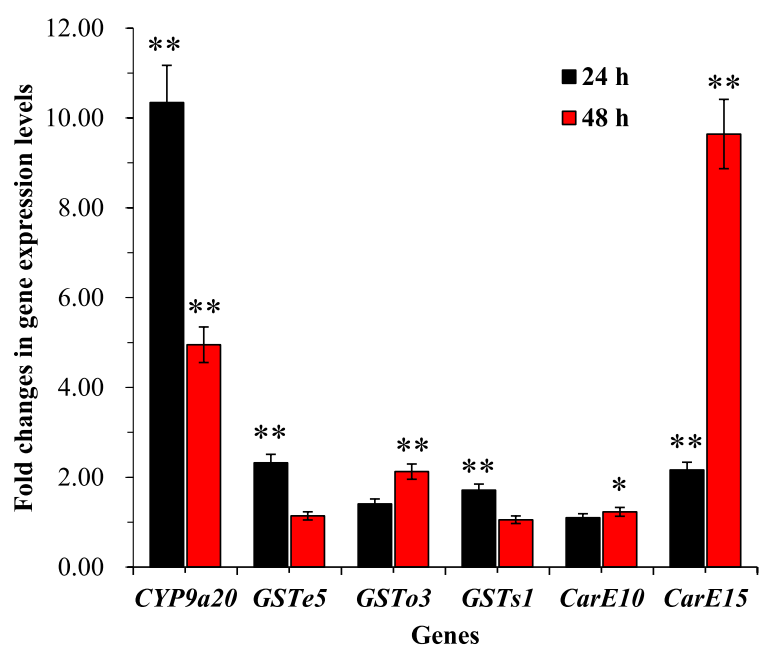

Fig. 5 Effects of pyriproxyfen exposure at $24 \mathrm{~h}$ and $48 \mathrm{~h}$ on the expression levels of detoxification enzymes-related genes in the midgut. Abscissa represents different genes, and ordinate represents fold changes in gene expression levels. The results are shown as the mean \pm S.E. Asterisks denote significant differences between the treatment and the control groups, as indicated by * $p \leqslant 0.05$, and $* * p \leqslant 0.01$.

used to determine the relative expression of some detoxification-related genes in the midgut of silkworm after pyriproxyfen exposure. It can be seen 
that the relative expressions of these genes were increased significantly at both $24 \mathrm{~h}$ and $48 \mathrm{~h}$. Compared with the control group, the expression levels of CYP9a20, GSTe5, GSTo3, GSTs1, CarE10, and CarE15 were significantly increased at $24 \mathrm{~h}$ by $10.35,2.33,1.40,1.71,1.10$, and 2.16 fold, respectively; and the levels were 4.95, 1.14, 2.13, $1.06,1.23$, and 9.64 times of those in the control group at $48 \mathrm{~h}$, respectively (Fig. 5).

\section{The activity of detoxification enzymes in the midgut}

To examine the effects of pyriproxyfen exposure on detoxification enzymes in the midgut, the activities of the main enzymes including P450, GST, and CarE were determined after pyriproxyfen treatment (Table 1). Compared with the control group, the activities of P450 enzymes were significantly increased at 48,72 , and $96 \mathrm{~h}$ in the treatment group ( $p \leqslant$ 0.05). At 24, 48, 72, and $96 \mathrm{~h}$ after treatment, the activities of GST enzymes were significantly increased to 2.01, 1.61, 2.07, and 2.73 fold of those of the control group $(p \leqslant 0.01)$, respectively. In addition, the CarE enzyme activity showed little changes at 24,48 , and $72 \mathrm{~h}$ after treatment, but it was increased by 1.19 fold at $96 \mathrm{~h}$ compared with the control group $(p \leqslant 0.05)$.

\section{DISCUSSION}

Silkworm is easily influenced by diseases and hostile environments, which directly affect the yield and the quality of cocoons. The midgut is the main organ of food digestion and nutrient absorption with multiple secreted enzymes. Histopathology results in our study showed that the muscle layer, the cylindrical cells, the goblet cells, and the peritrophic matrix of the midgut were all damaged after pyriproxyfen exposure. It has been known that the cylindrical cells of the midgut are the main components of the epithelial layer that secrete digestive juice and absorb nutrients, while the goblet cells only secrete digestive juice. The peritrophic matrix is an important barrier to protect the midgut from poison [13]. When the silkworm is attacked by viruses and other exogenous substances, the peritrophic matrix will cause serious lesions, thus affecting the normal digestion and absorption of the silkworm. Accordingly, we speculated that the damage to the muscle layer, the cylindrical cells, the goblet cells, and the peritrophic matrix of the midgut could be one of the main reasons for the inhibition of digestion, absorption, and growth of silkworm after pyriproxyfen exposure.
Carbohydrate is the main energy source of life activities. As the catalyst of carbohydrate hydrolysis, amylase plays an important role in carbohydrate metabolism [14]. The starch and dextrin in mulberry leaves are broken down into glucose, the energy source of its life activities and material basis, under the action of $\alpha$-amylase secreted by the midgut cells. Owing to this important role in carbohydrate metabolism, $\alpha$-amylase is one of the most pivotal digestive enzymes in silkworms [15]. Our study showed that the relative expression of $\alpha$-amylase in the treatment group was lower than that in the control group, suggesting the impacts of pyriproxyfen on the secretion of $\alpha$-amylase by the midgut cells of silkworm and the metabolism of carbohydrates (Fig. 2). In the midgut of Lepidoptera larvae, tryptase participates in proteolysis that promotes the cleavage of the peptide chain [15-18], which is particularly essential for digestion. We also showed that the expression of Trypsin-like protease in the treatment group decreased compared with the control group, suggesting the regulation of protein hydrolysis and the digestion of the midgut. In 2003, Ponnuvel et al isolated Lipase 1 from the digestive fluid of silkworm for the first time [19]. Given the specific expression of the Lipase 1 gene in the midgut of the silkworm, it has been suggested that Lipase 1 has the basic function of hydrolysis in the digestive tract of the silkworm, and plays an important role in the regulation of physiological function [20]. In this study, the relative expression of Lipase 1 in the treatment group decreased significantly, indicating the effects of pyriproxyfen exposure on the digestion of nutrients and the regulation of physiological functions.

ROS is a byproduct of normal oxygen metabolism, which plays an important role in cell signal transduction. While maintaining the normal metabolism of the body, excessive ROS could damage the body to a certain degree $[21,22]$. The oxidative phosphorylated electron transfer chain (ETC) in mitochondria is considered to be one of the main sources of ROS [23]. By detecting the isolated mitochondria, two ROS forming sites were located in complexes I and III [24]. NADH dehydrogenase (NDUFC1, NDUFC2, and NDUFB7) and cytochrome oxidase (QCR7, QCR8, and QCR9) are complexes I and III in the oxidative phosphorylation pathway, respectively $[25,26]$. We found that the relative expressions of NDUFC1, NDUFC2, NDUFB7, QCR7, QCR8, and QCR9 decreased at mRNA level after $24 \mathrm{~h}$ and $48 \mathrm{~h}$ of pyriproxyfen exposure. Therefore, we speculated that pyriproxyfen can inhibit the 
Table 1 Detoxification enzyme activities in the midgut of $B$. mori exposed to pyriproxyfen.

\begin{tabular}{|c|c|c|c|c|c|c|}
\hline \multirow{3}{*}{$\begin{array}{l}\text { Exposed time } \\
\text { (h) }\end{array}$} & \multicolumn{6}{|c|}{ Enzyme activity (U/g prot) } \\
\hline & \multicolumn{2}{|c|}{ P450 } & \multicolumn{2}{|c|}{ GST } & \multicolumn{2}{|c|}{ CarE } \\
\hline & Control & Pyriproxyfen & Control & Pyriproxyfen & Control & Pyriproxyfen \\
\hline 0 & $24.25 \pm 1.15$ & $24.71 \pm 1.24$ & $155.88 \pm 8.74$ & $165.06 \pm 9.12$ & $0.74 \pm 0.03$ & $0.75 \pm 0.04$ \\
\hline 24 & $24.34 \pm 1.65$ & $25.52 \pm 1.32$ & $159.20 \pm 9.89$ & $320.45 \pm 18.61^{* * *}$ & $0.76 \pm 0.07$ & $0.77 \pm 0.02$ \\
\hline 48 & $24.47 \pm 0.92$ & $27.38 \pm 1.66^{*}$ & $204.29 \pm 10.72$ & $329.07 \pm 19.08^{* * *}$ & $0.76 \pm 0.10$ & $0.74 \pm 0.08$ \\
\hline 72 & $24.49 \pm 0.89$ & $29.11 \pm 1.58^{*}$ & $188.57 \pm 9.55$ & $390.01 \pm 21.39^{* * *}$ & $0.73 \pm 0.08$ & $0.75 \pm 0.05$ \\
\hline 96 & $26.08 \pm 1.33$ & $29.59 \pm 1.90^{*}$ & $148.64 \pm 7.39$ & $405.72 \pm 25.84^{* * *}$ & $0.81 \pm 0.12$ & $0.96 \pm 0.14^{*}$ \\
\hline
\end{tabular}

The experiments were performed in three replicates. The significance of differences is indicated by * $p \leqslant 0.05$, and $* * p \leqslant 0.01$.

activity of ETC complexes I and III and destroy the ETC, leading to the accumulation of ROS and subsequently causing a certain degree of damage to the body. Furthermore, we found that the expression of $A T P E O D$ at mRNA level decreased significantly at $24 \mathrm{~h}$ and $48 \mathrm{~h}$ after pyriproxyfen exposure. Because of the participation of ATPase in energy conversion [27], we speculated that digestive and absorption disorders in the midgut of silkworms could be associated with the inhibition of pyriproxyfen on ATP synthesis and energy metabolism.

When the active oxygen metabolism in an organism is under extreme environmental stresses such as bacteria, viruses, high temperature, low temperature, ultraviolet radiation, $\mathrm{SO}_{2}$ in the air, etc., this imbalance will lead to the production of excessive ROS [28]. Particularly, the loss of ROS metabolism balance leads to damages of the oxidative and the immune systems. Therefore, the elimination of excessive reactive oxygen radicals in higher organisms is essential for them to resist the adverse environment and to improve their immunity. In the long-term evolution process, in order to avoid oxidative damages, organisms have formed a relatively complete protection system, the antioxidant system, to maintain the redox balance. They can adjust their metabolism in accordance with environmental changes to achieve the accordant heritability changes. Silkworm, as an important economic insect and a representative of Lepidoptera, is no exception [29]. In the present study, we found that the relative expressions of SOD, CAT, GST, and GPX in the treatment group at $24 \mathrm{~h}$ and $48 \mathrm{~h}$ were lower than those in the control group. As an important antioxidant enzyme, superoxide dismutase (SOD) is the only enzyme that directly metabolizes superoxide ROS [30]. SOD is a member of the antioxidant system for ROS removal. It con- verts oxygen anion to $\mathrm{H}_{2} \mathrm{O}_{2}$, which is then removes by CAT [31]. CAT plays an important role in cell senescence and apoptosis, and its role in metabolism has attracted more attention, especially in the physiological functions of insects. Many studies have found that CAT enhances the resistance of insects. GST can remove $\mathrm{H}_{2} \mathrm{O}_{2}$ and organic peroxides. GPX can use reduced glutathione or AOS (activated oxygen species) as an electron donor to catalyze the reduction of $\mathrm{H}_{2} \mathrm{O}_{2}$ or organic peroxide to water and corresponding alcohol [32]. In the present study, we found that the relative expressions of $S O D, C A T$, GST and GPX in the treatment group at $24 \mathrm{~h}$ and $48 \mathrm{~h}$ were lower than those in the control group. We thus speculated that the antioxidant defense system in the midgut of the silkworm could be destroyed by pyriproxyfen, which will cause oxidative damage and disruption of immune system.

In order to survive, organisms must have certain physiological, biochemical, and even behavioral adaptabilities [33]. The main and common adaptive mechanism of detoxification in organisms is the decomposition of metabolites or heterologous substances through the detoxifying enzyme system [34]. The insect detoxifying enzyme system is rather heterogeneous, which can metabolize a large number of endogenous or exogenous substrates [35]. The change of detoxification-related genes in insects at the transcription level leads to the change of the enzyme activities, thus changing the metabolic detoxification ability of the insect to pesticides. In this study, the activities of detoxifying enzymes and the expression levels of the related genes were measured. The results showed that the expression level of CYP9a2O was significantly upregulated at $24 \mathrm{~h}$ and $48 \mathrm{~h}$. Consistently, P450 enzyme activity was also increased compared with the control group, indicating its critical role in the midgut detoxification. In addition, at $24 \mathrm{~h}$ and $48 \mathrm{~h}$, 
the transcription levels of GSTe5, GSTo3, and GSTs1 were up-regulated. This trend of gene expression was in line with the significantly increased activity of the GST enzyme, which also played a major role in the midgut detoxification process after pyriproxyfen exposure. In addition, the transcription levels of CarE10 and CarE15 increased at $24 \mathrm{~h}$ and $48 \mathrm{~h}$ after pyriproxyfen exposure, while the enzyme activity of CarE increased significantly only at $96 \mathrm{~h}$ after exposure. In general, the exposure of pyriproxyfen can significantly affect the activity of detoxifying enzymes and the expression of related genes in the midgut of the silkworm, indicating its considerable role in the midgut detoxification of silkworm.

\section{CONCLUSION}

Low dose of pyriproxyfen at $0.001 \mathrm{mg} / 1$ is toxic to silkworm, inducing the inhibition of digestive absorption, energy metabolism, and antioxidant enzyme systems in the insect midgut. In addition, we found that the activity of detoxifying enzymes and the expression of the related genes increased, suggesting the enhanced detoxification ability of the silkworm midgut by pyriproxyfen, as well as the resistance of silkworm to pyriproxyfen. In general, our study revealed the response of the silkworm midgut to pyriproxyfen, providing a conclusive reference to understand the insect's metabolic mechanism.

\section{Appendix A: Supplementary data}

Supplementary data associated with this article can be found at http://dx.doi.org/10.2306/ scienceasia1513-1874.2021.108.

Acknowledgements: This work was supported by the Foundation of Post Scientist in National Sericultural System (CARS-18-ZJ0101) and the Natural Science Foundation of Jiangsu Province (BK20181228, BK20201229). We would like to thank TopEdit (www.topeditsci.com) for English language editing of this manuscript.

\section{REFERENCES}

1. Nath BS (2000) Changes in carbohydrate metabolism in hemolymph and fat body of the silkworm, Bombyx mori L. exposed to organophosphorus insecticides. Pestic Biochem Phys 68, 127-137.

2. Zhang Y, Tang F, Shao Y, Zhu F, Bai X (2019) Molecular epidemiology of Bombyx mori nucleopolyhedrovirus in Yunnan sericulture region, China. ScienceAsia 45, 332-341.

3. Ishaaya I, Horowitz AR (1992) Novel phenoxy juvenile hormone analog (pyriproxyfen) suppresses embryogenesis and adult emergence of sweetpotato whitefly (Homoptera: Aleyrodidae). J Econ Entomol 85, 2113-2117.

4. Aribi N, Smagghe G, Lakbar S, Soltani-Mazouni N, Soltani N (2006) Effects of pyriproxyfen, a juvenile hormone analog, on development of the mealworm, Tenebrio molitor. Pestic Biochem Phys 84, 55-62.

5. Maharajan K, Muthulakshmi S, Nataraj B, Ramesh M, Kadirvelu K (2018) Toxicity assessment of pyriproxyfen in vertebrate model zebrafish embryos (Danio rerio): A multi biomarker study. Aquat Toxicol 196, 132-145.

6. Wang YH, Gu ZY, Wang JM, Sun SS, Wang BB, Jin YQ, Shen WD, Li B (2013) Changes in the activity and the expression of detoxification enzymes in silkworms (Bombyx mori) after phoxim feeding. Pestic Biochem Phys 105, 13-17.

7. Gu ZY, Zhou Y, Xie Y, Li F, Bing L (2014) The adverse effects of phoxim exposure in the midgut of silkworm, Bombyx mori. Chemosphere 96, 33-38.

8. Zhao GD, Zhang YL, Liu YL, Li B, Chen YH, Xu YX (2015) Promoter analysis and RNA interference of CYP6ab4 in the silkworm Bombyx mori. Mol Genet Genomics 290, 1943-1953.

9. Li FC, Ni M, Zhang H, Wang BB, Xu KZ, Tian JH (2014) Expression profile analysis of silkworm P450 family genes after phoxim induction. Pestic Biochem Phys 122, 103-109.

10. Qian HY, Zhang X, Zhao GD, Guo HM, Li G, Xu AY (2020) Effects of pyriproxyfen exposure on reproduction and gene expressions in silkworm, Bombyx mori. Insects 11, 467-479.

11. Sun HY, Chen WG, Dong RH, Dai JZ (2008) The toxicity test of the $10 \%$ EC pyriproxyfen on silkworm. Bull Seric 39, 18-20.

12. Saad MSI, Helaly WMM, El-Sheikh ESA (2019) Biological and physiological effects of pyriproxyfen insecticide and amino acid glycine on silkworm, Bombyx mori L. Bull Natl Res Centre 43, 145-152.

13. Mitsuhashi W, Miyamoto K (2003) Disintegration of the peritrophic membrane of silkworm larvae due to spindles of an entomopoxvirus. J Invertebr Pathol 82, 34-40.

14. Hickey DA (1979) The geographical pattern of an enzyme polymorphism in $D$. melanogaster. Genetica $51,1-4$.

15. Aghajari N, Haser R, Feller G, Charles G (2010) Crystal structures of the psychrophilic alpha-amylase from Alteromonas haloplanctis in its native form and complexed with an inhibitor. Protein Sci 7, 564-572.

16. Li HR, Oppert B, Higgins RA, Huang F, Zhu KY, Buschman LL (2004) Comparative analysis of proteinase activities of Bacillus thuringiensis-resistant and -susceptible Ostrinia nubilalis (Lepidoptera: Crambidae). Insect Biochem Molec 34, 753-762.

17. Jiang H, Kanost MR (2000) The clip-domain family of serine proteinases in arthropods. Insect Biochem Molec 30, 95-105. 
18. Oppert B (1999) Protease interactions with Bacillus thuringiensis insecticidal toxins. Arch Insect Biochem 42, 1-12.

19. Ponnuvel KM, Nakazawa H, Furukawa S, Asaoka A, Ishibashi J, Tanaka H (2003) A lipase isolated from the silkworm Bombyx mori shows antiviral activity against nucleopolyhedro virus. J Virol 77, 10725-10729.

20. Xia DG, Zhang TT, Zhao QL, Zhang GZ, Qiu ZY, Zhang YS (2017) Promoter activity analysis of Bombyx mori lipase-1 gene. Sci Seric 43, 395-401.

21. Kumar S, Christophides GK, Cantera R, Charles B, Han YS, Meister S, Dimopoulos G, Kafatos FC (2003) The role of reactive oxygen species on Plasmodium melanotic encapsulation in Anopheles gambiae. Proc Natl Acad Sci USA 100, 14139-14144.

22. Apel K, Hirt H (2004) Reactive oxygen species: metabolism, oxidative stress, and signal transduction. Annu Rev Plant Biol 55, 373-399.

23. Loschen G, Flohe L, Chance B (1971) Respiratory chain linked $\mathrm{H}_{2} \mathrm{O}_{2}$ production in pigeon heart mitochondria. FEBS Lett 18, 261-264.

24. Liu YB, Gary F, David S (2002) Generation of reactive oxygen species by the mitochondrial electron transport chain. $J$ Neurochem 80, 780-787.

25. Chen Q, Vazquez EJ, Moghaddas S, Hoppel CL, Lesnefsky EJ (2003) Production of reactive oxygen species by mitochondria: Central role of complex III. $J$ Biol Chem 278, 36027-36031.

26. Bleier L, Wittig I, Heide H, Steger M, Brandt U, Dröse S (2015) Generator-specific targets of mitochondrial reactive oxygen species. Free Radical Bio Med 78, $1-10$.

27. Turrens JF (2003) Mitochondrial formation of reactive oxygen species. $J$ Physiol 552, 335-344.
28. Andreyev AY, Kushnareva YE, Starkov AA (2005) Mitochondrial metabolism of reactive oxygen species. Biochemistry (Moscow) 70, 246-264.

29. Kanzok SM (2001) Substitution of the thioredoxin system for glutathione reductase in Drosophila melanogaster. Science 291, 643-646.

30. Van Raamsdonk JM, Hekimi S (2012) Superoxide dismutase is dispensable for normal animal lifespan. Proc Natl Acad Sci USA 109, 5785-5790.

31. Parker JD, Parker KM, Keller L (2004) Molecular phylogenetic evidence for an extracellular $\mathrm{Cu} \mathrm{Zn}$ superoxide dismutase gene in insects. Insect Mol Biol 13, 587-594.

32. Kim YJ, Jang MG, Noh HY, Lee HJ, Sukweenadhi J, Kim JH, Kim SY, Kwon WS, et al (2014) Molecular characterization of two glutathione peroxidase genes of Panax ginseng and their expression analysis against environmental stresses. Gene 535, 33-41.

33. Zhao GD, Zhang X, Wang CT, Zhang HT, Guo HM, Qian HY, et al (2020) Effect of pyriproxyfen exposure on cocooning and gene expression in the silk gland of Bombyx mori (Linnaeus, 1758). Ecotox Environ Safe 202, 914-921.

34. Mao TT, Li FC, Fang YL, Wang H, Chen J, Li MX, Lu ZT, Qu JW, et al (2019) Effects of chlorantraniliprole exposure on detoxification enzyme activities and detoxification-related gene expression in the fat body of the silkworm, Bombyx mori. Ecotox Environ Safe 176, 58-63.

35. Zhao GD, Guo HM, Zhang HT, Zhang X, Qian HY, Li G, Xu AY (2020) Effects of pyriproxyfen exposure on immune signaling pathway and transcription of detoxification enzyme genes in fat body of silkworm, Bombyx mori. Pestic Biochem Phys 168, 4621-4628. 


\section{Appendix A. Supplementary data}

Table S1 Primer sequences for qRT-PCR.

\begin{tabular}{|c|c|c|c|}
\hline Gene name & Accession No. & Primer sequence $\left(5^{\prime}-3^{\prime}\right)$ & Produce size (bp) \\
\hline Actin3 & NM_001126254.1 & $\begin{array}{l}\text { F: CGGCTACTCGTTCACTACC } \\
\text { R: CCGTCGGGAAGTTCGTAAG }\end{array}$ & 147 \\
\hline$\alpha$-amylase & NM_001173153.1 & $\begin{array}{l}\text { F: ATCCTGCTGTTCCTTACGGC } \\
\text { R: TGTCAGGGCAGCAGTTGTAG }\end{array}$ & 178 \\
\hline Trypsin-like protease & NM_001046885.1 & $\begin{array}{l}\text { F: GGTCCATCAAGTGAGCCGAT } \\
\text { R: AATGACCACTACCGAGCCAC }\end{array}$ & 212 \\
\hline Lipase1 & XM_004932287.2 & $\begin{array}{l}\text { F: ACTTCTTCGTTCTCCCTCGC } \\
\text { R: CGGGTATGACGAAAGCGTTG }\end{array}$ & 167 \\
\hline NDUFV1 & XM_004934174.2 & $\begin{array}{l}\text { F: ATGGAGGTTGAAGGGTGCTC } \\
\text { R: ACGATCCAGTCGGTTCCTTTC }\end{array}$ & 168 \\
\hline NDUFB7 & XM_004926400.2 & $\begin{array}{l}\text { F: GCTTCTTTATCGATGCGCCC } \\
\text { R: GGCGACGTTCCCGTTCAAAT }\end{array}$ & 178 \\
\hline NDUFC2 & XM_004926501.2 & $\begin{array}{l}\text { F: TACGTTCGGTATTGGCACAGG } \\
\text { R: TTGGATACCGCTGAACACTGG }\end{array}$ & 167 \\
\hline QCR7 & NM_001045492.1 & $\begin{array}{l}\text { F: GGGCCTACAATCTTTCGGGA } \\
\text { R: AAGTCTGCGGAGTGCTTCAG }\end{array}$ & 169 \\
\hline QCR8 & XM_004927834.2 & $\begin{array}{l}\text { F: CCCGCCCTTCATCATTGGAT } \\
\text { R: ATCAGCAGGGTTCTTCCGTG }\end{array}$ & 167 \\
\hline QCR9 & XM_004928783.2 & $\begin{array}{l}\text { F: GACCAGTTTCGAGCTTTGACG } \\
\text { R: AGACCACACGGACATTTTGA }\end{array}$ & 170 \\
\hline ATPeVOD & NM_001046964.1 & $\begin{array}{l}\text { F: CCGAGTTGAACGGGCGTAAA } \\
\text { R: AAGCCCTCCAAATACCCAGC }\end{array}$ & 167 \\
\hline$S O D$ & NM_001043619.1 & $\begin{array}{l}\text { F: TCCTCAAGCACCTACACC } \\
\text { R: GATAGCCAATGATACACG }\end{array}$ & 216 \\
\hline GST & NM_001043509.2 & $\begin{array}{l}\text { F: TTGAACCCTCAACACACGGT } \\
\text { R: GCCTTTGGCGTACTTGTTCA }\end{array}$ & 102 \\
\hline$G P X$ & NM_001043534.1 & $\begin{array}{l}\text { F:CTGGTCAAGAGCCTGGCAATCC } \\
\text { R: GCCGTGGCGTTCAACTGGAA }\end{array}$ & 221 \\
\hline CAT & NM_001043447.1 & $\begin{array}{l}\text { F: AAACGGTGGGCAAGAATGGT } \\
\text { R: TCGTTCTGGAATACGCTCCC }\end{array}$ & 92 \\
\hline СYР9a20 & EF421989 & $\begin{array}{l}\text { F: CTCGGATTTCTTCCACCAG } \\
\text { R: TGTGGACAGACGATGACTTGG }\end{array}$ & 144 \\
\hline GSTe5 & NM_001114992.1 & $\begin{array}{l}\text { F: GCGGCGAGAAAGAAATACG } \\
\text { R: CTGATGGAAGTAACGCAGCAA }\end{array}$ & 139 \\
\hline GSTo3 & NM_001046970.1 & $\begin{array}{l}\text { F: CTCCGACACTGTCAATGAGGA } \\
\text { R: CTCGAACCAAGGCCATATCAT }\end{array}$ & 145 \\
\hline GSTs1 & NM_001043612.1 & $\begin{array}{l}\text { F: GACATGGGGTGATTTCGTG } \\
\text { R: AGCCTTCACTTTGGGCTGT }\end{array}$ & 136 \\
\hline CarE10 & EU523535 & $\begin{array}{l}\text { F: ACAGAGTGCTGGAGGAAC } \\
\text { R: CAGATTGGCTGACGATTA }\end{array}$ & 129 \\
\hline CarE15 & EU727141.1 & $\begin{array}{l}\text { F: ACTTCGCGTGAATTTCGT } \\
\text { R: TATTTGCCTACCGCCTCT }\end{array}$ & 142 \\
\hline
\end{tabular}

